\title{
(DIS)PARIDADES DE GÊNERO AO NÍVEL DAS SENTENÇAS JUDICIAIS: UMA REVISÃO ESTRUTURADA DA LITERATURA
}

\author{
Catarina Sofia Pereira Paula ${ }^{1}$, Sónia Maria Martins Caridade ${ }^{2}$
}

Resumo: Com esta revisão estruturada da literatura pretendeu-se analisar as disparidades nas sentenças judiciais que envolvem mulheres agressoras. Foi efetuada uma pesquisa em diversas bases de dados eletrónicas, acedendo-se a um total de 30 artigos. A análise destes diferentes estudos permitiu perceber que ainda são escassos os trabalhos de investigação nesta área. Entre os diferentes fatores com potencial influência no resultado das sentenças judiciais, identificaram-se: idade, existência de filhos, raça, tipo de crime praticado, escolaridade e antecedentes criminais. Concluiu-se pela necessidade de haver transformações nas práticas sociais e jurídicas, promovendo a eficácia normativa e a credibilização do sistema judicial.

\author{
Palavras-chave: Crime no feminino. \\ Disparidades nas sentenças. Gênero. \\ Sistema de justiça criminal.
}

\begin{abstract}
The aim of this structured review was to analyze the disparities in judicial sentences involving women offenders. A search through multiple electronic databases was carried out, accessing a total of 30 articles. The analysis of these different studies allowed for the conclusion that there are few investigative works in this area. Amongst the different factors that influence the judicial sentences, the following were identified: age, having children, race, type of crime committed, schooling and criminal record. It was concluded that there is a need to transform the judicial and social practice, promoting the normative efficiency and the credibility of the judicial system.
\end{abstract}

\footnotetext{
${ }^{1}$ Faculdade de Ciências Humanas e Sociais; Universidade Fernando Pessoa

${ }^{2}$ Doutorada em Psicologia da Justiça pela Universidade do Minho. Professora Auxiliar na Universidade Fernando Pessoa (UFP) do Porto, Portugal. Co-coordenadora da Unidade de Psicologia Forense da Clínica Pedagógica de Psicologia da UFP e investigadora no Observatório Permanente Violência e Crime desta mesma universidade. Desenvolveu a sua tese de doutoramento na área da violência das relações íntimas juvenis e é autora de diversas publicações, nacionais e internacionais, neste domínio e nas áreas da Psicologia da Justiça e Vitimologia. É revisora em várias revistas nacionais e internacionais
} 
Key-words: Female crime. Sentences disparities. Gender. Criminal justice system.

\section{(Des)igualdade(s) de género e atitudes}

\section{face à conduta (criminal) feminina}

A(s) (des)igualdade(s) de género, ainda muito impregnadas no processo de socialização dos indivíduos, ditam expectativas diferenciadas acerca do que é ou não aceitável nas condutas feminina e masculina. Por conseguinte, tais expectativas influenciam os pensamentos e comportamentos dos indivíduos, assim como a sua posição e avaliação em torno das questões de género e, em particular da sexualidade (Page, 2008). Esta diferenciação social assenta fundamentalmente no essencialismo biológico e, portanto, naquelas que constituem as principais diferenças sexuais entre homens e mulheres; é geralmente veiculada através de preconceitos e estereótipos de género, promovendo práticas discriminatórias - discriminação de género (Amâncio, 1994, Nogueira, 2001).

Historicamente homens e mulheres sempre foram socializados para o desempenho de distintos papéis de género (e em que, por exemplo, os homens são estimulados a adotar um comportamento mais agressivo, dominador e as mulheres desafiadas a comportamentos de maior passividade e submissão face ao outro), repercutindose nas atitudes face ao crime feminino e masculino (Page, 2008). Assim, e se por um lado, os estereótipos de género atribuídos à mulher (e.g., frágil, débil, mais credível, maternal, etc.), parecem inviabilizar a sua potencial conduta criminal, por outro lado, a frequente associação entre transgressão, violência e masculinidade promovem estereótipos de género que escamoteiam a possibilidade de homens e mulheres experienciarem e usarem a violência por diferentes razões, circunstâncias e como resultado de histórias e contextos de pertença de género distintos (Duarte, 2012). Esta sub-representação ou relativização da conduta transgressiva feminina poderá enviesar a atuação dos profissionais neste domínio, determinando com a forma como estes percecionam o (menor) envolvimento feminino no crime e o tipo de avaliação do risco que efetuam, bem como na delineação de políticas de prevenção e intervenção face à conduta criminal feminina (cf. Caridade e Nunes, 2017). 
De notar que os dados oficiais dos últimos anos têm vindo a documentar um elevado aumento do crime no feminino, um pouco por todo o mundo. Tal tem motivado um incremento e progressivo interesse por parte da comunidade científica em desocultar esta realidade, empregando esforços para investigar a conduta criminal feminina e, deste modo, proceder a uma caracterização do problema e suas especificidades (cf. Caridade e Nunes, 2017). Deste modo, diferentes pesquisas têm surgido no sentido de procurar analisar a relação da mulher com o crime em função da evolução do seu papel na sociedade, fundamentalmente baseado naquele que é o ideal de feminilidade socialmente estabelecido. Este ideal de mulher tem sido sobretudo associado à noção de família e aos papéis cujo desempenho se espera desta neste contexto ao longo dos tempos, nomeadamente as tarefas respeitantes à conjugalidade e à maternidade (Matos, 2008). Tem sido, assim, defendido que a análise da conduta transgressiva feminina é indissociável destes discursos sociais que veiculam diversos estereótipos de gênero. Por sua vez, a forma como o sistema de controlo formal opera é igualmente permeável às práticas e discursos sociais vigentes e difundidos nas diversas esferas da vida em sociedade (família, política, religião, ciência) (Machado, 2004), incidindo de forma mais particular sobre 0 comportamento feminino. A forma como os aludidos estereótipos de gênero ou tipificações, baseadas em padrões de conduta algo moralistas (e muito em função da conduta sexual feminina) tendem a influenciar as tomadas de decisão judicial, tem motivado algum debate científico (Machado, 2004) e até social, o qual apresentamos sumariamente.

\section{Gênero e (dis)paridades nas sentenças judiciais}

Vários trabalhos têm emergido no sentido de analisar as disparidades registadas ao nível das sentenças judiciais em função do gênero dos infratores criminais (cf. Cauffman, 2008; Philippe, 2017), e os quais têm permitido perceber que a tomada de decisão judicial varia consoante o gênero do ofensor, sugerindo-se que as mulheres ora recebem penas mais leves ora são mais severamente punidas. Esta dualidade de critérios ao nível da tomada de decisão judicial tem motivado algum 
debate no sentido de procurar perceber em que circunstâncias o sistema é mais leniente ou mais punitivo para com a mulher ofensora (Cauffman, 2008).

De entre as diversas tentativas existentes para tentar compreender esta disparidade e discriminação identificadas nas sentenças judiciais (cf. Jeffries, 2002) destacam-se: a hipótese explicativa que aponta para um certo cavalheirismo/paternalismo face à mulher ofensora, considerando-se que a sustentação de certos estereótipos de gênero em relação à mulher (e.g., como sendo mais frágil, vulnerável, dependente do homem) promovem o dever de o homem proteger a mulher, explicando-se, deste modo, o recurso a uma certa leniência nas medidas que lhe são aplicadas. Contudo, as mulheres que enveredam por crimes tidos como sendo tipicamente masculinos (e.g., crimes sexuais) e que colidem com o ideal de feminilidade socialmente estabelecido, já são percebidas como não sendo merecedoras de qualquer tipo de proteção, não se aplicando esta tese do cavalheirismo, podendo nestes casos, ser alvo de medidas muito mais severas (Albonneti, 1998 citado por Franklin e Fearn, 2008). Por sua vez, identifica-se a abordagem centrada no conflito de gênero - Gender conflict -, apoiada nos princípios gerais da teoria do conflito e que defende que o grupo social detentor do poder e da autoridade elabora e promulga leis de forma a reter esse mesmo poder no seio do grupo social dominante forçando a subordinação dos restantes, estando as mulheres incluídas neste grupo social subordinado (Daly, 1989). Esta abordagem sustenta, deste modo, que o sistema de justiça funciona com um mecanismo de execução desta normativa social e trata e sanciona as mulheres em conformidade (Franklin e Fearn, 2008).

A presente revisão estruturada da literatura tem como principal objetivo identificar e caraterizar os estudos com enfoque nas disparidades ao nível das sentenças judiciais que envolvem mulheres agressoras. Pretendemos, deste modo, mapear e sistematizar o que tem vindo a ser debatido sobre este fenómeno nomeadamente identificar os principais fatores que são considerados na atribuição de sentenças judiciais a mulheres que praticaram algum tipo de crime.

\section{Metodologia}

A revisão estruturada da literatura assentou em uma pesquisa organizada e 
planificada nas línguas inglesa, espanhola e portuguesa, nas seguintes bases de dados eletrónicas: B-on, SciELO, ResearchGate, Portsmouth library database, Sage, Science Direct, Oxford Handbooks online e Springer. Neste sentido, procedeu-se ao cruzamento de diferentes palavraschaves, nas diferentes línguas já referenciadas, usando termos como: disparidades nas sentenças, crimes femininos, diferenças de gênero e sistema de justiça criminal de modo a localizar os artigos potencialmente relevantes. Foi também utilizado o motor de pesquisa Google, recorrendo à mesma combinação de palavras-chave, de forma a integrar outros trabalhos de relevância sobre o tema e publicações encontradas através do método snowball, que não constassem das bases de dados referidas anteriormente.

Subsequentemente e sempre que um artigo era identificado, através da leitura do título como sendo relevante para a pesquisa, procedíamos à leitura do resumo de forma a perceber se o mesmo se adequava aos critérios de inclusão e exclusão previamente definidos. Relativamente aos critérios de inclusão apenas foram considerados estudos, de natureza qualitativa e/ou quantitativa, com enfoque na análise de sentenças relativas a elementos de sexo feminino e maiores de idade. Os critérios de exclusão envolveram: artigos de análise de sentenças apenas relativas a elementos de sexo masculino ou que se referissem a elementos de sexo feminino menores de idade; de igual modo, foram excluídos trabalhos de revisão da literatura neste domínio.

A pesquisa foi iniciada a 30 de setembro de 2017 e concluída a 28 de fevereiro de 2018. Dos artigos consultados apenas 30 estudos corresponderam aos critérios desejados. $\mathrm{Na}$ secção dos resultados serão apresentados todos os detalhes a respeito dos artigos que integram a presente revisão estruturada. 


\section{Tabela 1}

Caracterização dos estudos acerca das disparidades nas sentenças judiciais envolvendo mulheres ofensoras

\begin{tabular}{|c|c|c|c|c|}
\hline Estudo & País & Objetivo & Amostra & Resultados/Conclusões \\
\hline $\begin{array}{l}\text { Kruttschnitt } \\
(1980-1981)\end{array}$ & E.U.A. & $\begin{array}{l}\text { Analisar a relação entre certos } \\
\text { fatores (e.g., antecedentes } \\
\text { criminais, idade, emprego) e a } \\
\text { severidade das penas } \\
\text { atribuídas. }\end{array}$ & 1.034 mulheres & $\begin{array}{l}\text { - A maior severidade das penas surgiu sobretudo associada à condição } \\
\text { económica desfavorecida da mulher, ao facto de possuir antecedentes } \\
\text { criminais ou de terem tido liberdade condicional; } \\
\text { - A menor severidade das penas foi encontrada em mulheres empregadas. }\end{array}$ \\
\hline $\begin{array}{l}\text { Kruttschnitt } \\
(1982)\end{array}$ & E.U.A. & $\begin{array}{l}\text { Compreender de que forma os } \\
\text { antecedentes criminais e vários } \\
\text { aspetos da vida do indivíduo } \\
\text { influenciavam na decisão } \\
\text { judicial. }\end{array}$ & 1.034 mulheres & $\begin{array}{l}\text { - Ter antecedentes criminais e historial psiquiátrico surgiu associado a uma } \\
\text { maior severidade das penas; } \\
\text { - Mulheres com antecedentes criminais, mas com um bom trabalho, sem } \\
\text { antecedentes de doenças mentais e dependências químicas foram sentenciadas } \\
\text { com menor severidade do que as que não apresentavam antecedentes } \\
\text { criminais, mas eram consideradas desviantes em outros aspetos da sua vida } \\
\text { (e.g. serem dependentes, relacionarem-se com indivíduos com } \\
\text { comportamentos desviantes, não ter emprego, etc). }\end{array}$ \\
\hline $\begin{array}{l}\text { Gruhl, Spohn e } \\
\text { Welch (1985) }\end{array}$ & E.U.A. & $\begin{array}{l}\text { Perceber se indivíduos de sexo } \\
\text { feminino beneficiam do } \\
\text { "paternalistic treatment". }\end{array}$ & $\begin{array}{l}27.000 \text { participantes } \\
\text { eram homens e } 1.965 \\
\text { mulheres }\end{array}$ & $\begin{array}{l}\text { - Indivíduos de sexo feminino (e especialmente mulheres de raça negra) } \\
\text { receberam tratamento paternalista numa primeira fase, sendo que no final da } \\
\text { pesquisa isto não se verificou; } \\
\text { - Identificaram-se sinais de discriminação racial em mulheres de raça negra. }\end{array}$ \\
\hline Daly (1987) & E.U.A. & $\begin{array}{l}\text { Analisar a influência do gênero } \\
\text { e enquadramento familiar nas } \\
\text { decisões judiciais. }\end{array}$ & $\begin{array}{l}2.004 \text { participantes, } \\
\text { sendo que cerca de } \\
220 \text { eram mulheres }\end{array}$ & $\begin{array}{l}\text { - Mulheres com filhos (solteiras ou casadas) apresentaram maior } \\
\text { probabilidade de receber uma sentença menos severa que mulheres sem } \\
\text { família. }\end{array}$ \\
\hline Daly (1989) & E.U.A. & $\begin{array}{l}\text { Identificar os fatores que os } \\
\text { juízes consideram na } \\
\text { atribuição de sentenças. }\end{array}$ & $\begin{array}{l}23 \text { juízes, dos quais } 20 \\
\text { eram homens e } 3 \text { eram } \\
\text { mulheres }\end{array}$ & $\begin{array}{l}\text { - As variáveis "trabalho" e "família" surgiram como sendo determinantes na } \\
\text { decisão da sentença, nomeadamente: o facto de o/a acusado/a constituir o } \\
\text { principal suporte da família e a existência de filhos e/ou dependentes; } \\
\text { - Ter filhos revelou ter um peso mais importante na decisão judicial do que } \\
\text { ser casado/a, principalmente no que diz respeito a mulheres. }\end{array}$ \\
\hline
\end{tabular}




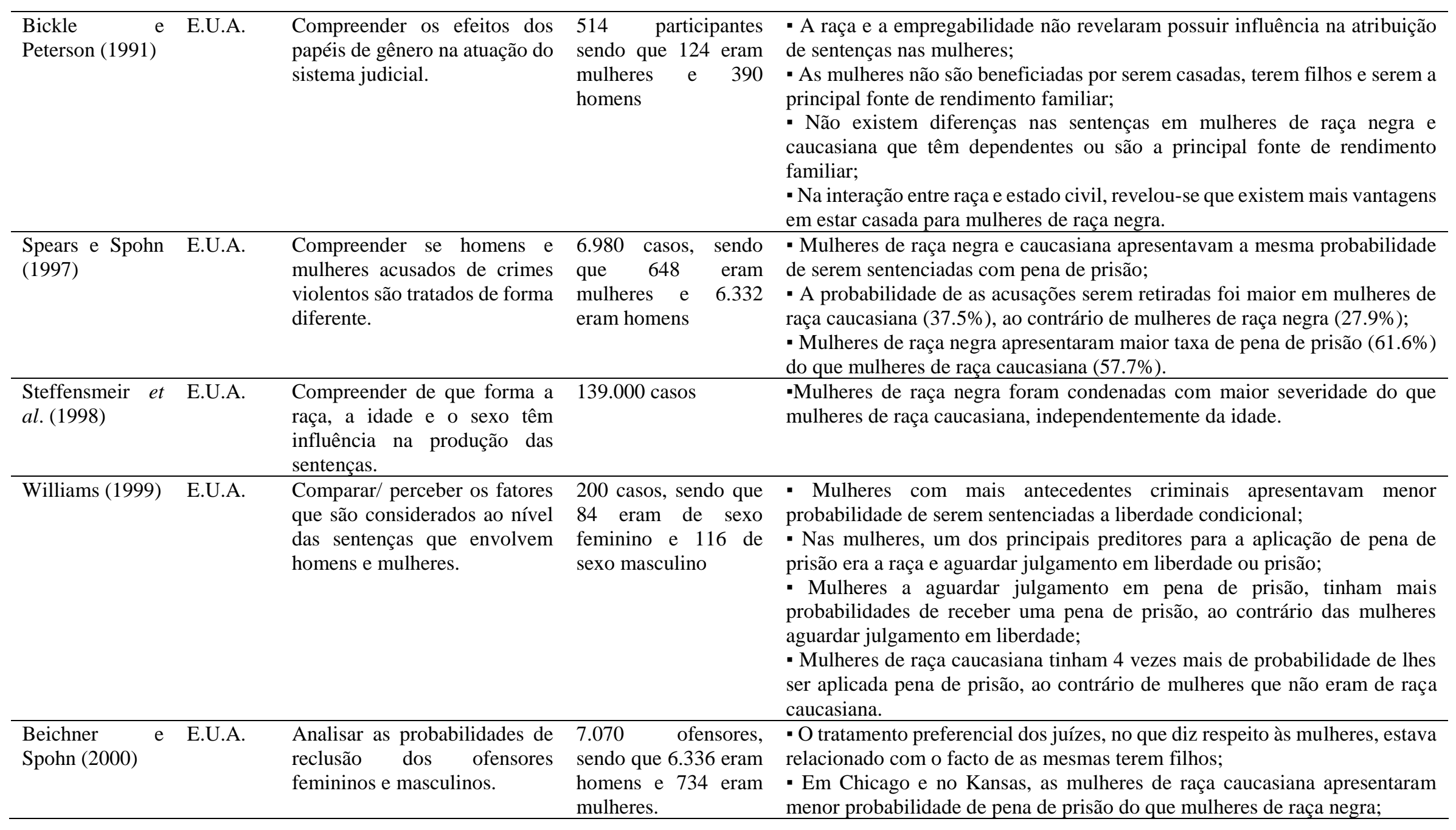


- Em Chicago e no Kansas, mulheres mais velhas apresentaram uma maior probabilidade de receber uma pena de prisão do que mulheres mais novas; -No Kansas, mulheres com filhos tinham menor probabilidade de serem sentenciadas a pena de prisão do que mulheres sem filhos;

- Mulheres de raça negra não eram tratadas de modo diferente das mulheres de raça caucasiana.

\begin{tabular}{lll}
\hline Albonetti (2002) & E.U.A. & $\begin{array}{l}\text { Compreender de que modo o } \\
\text { sexo influencia na longevidade }\end{array}$
\end{tabular} da pena de prisão.

3.217 participantes, sendo 1.643 de sexo feminino e 11.574 de sexo masculino

\begin{tabular}{|c|c|c|c|c|}
\hline $\begin{array}{l}\text { Koons-Witt } \\
(2002)\end{array}$ & E.U.A. & $\begin{array}{l}\text { Examinar em que medida o } \\
\text { sexo tem influência nos } \\
\text { resultados das sentenças após a } \\
\text { implementação de "sentencing } \\
\text { guidelines". }\end{array}$ & $\begin{array}{l}835 \text { participantes, dos } \\
\text { quais } 453 \text { de sexo } \\
\text { masculino e } 382 \text { de } \\
\text { sexo feminino }\end{array}$ & $\begin{array}{l}\text { - Mulheres com filhos tinham menor probabilidade de receber pena de prisão } \\
\text { do que mulheres sem filhos; } \\
\text { - Mulheres enquadradas nos papéis de gênero tracionais tinham maior } \\
\text { propensão a receber sentenças menos severas e a serem sancionadas com } \\
\text { serviço comunitário; } \\
\text { - Mulheres que não eram caucasianas apresentaram maior propensão para } \\
\text { receber medidas comunitárias ao contrário de mulheres de raça caucasiana. }\end{array}$ \\
\hline $\begin{array}{l}\text { Griffin } \\
\text { Wooldredge } \\
\text { (2006) }\end{array}$ & E.U.A. & $\begin{array}{l}\text { Analisar em que medida o sexo } \\
\text { pode estar relacionado com o } \\
\text { encarceramento após a } \\
\text { implementação } \\
\text { "sentencing guidelines". }\end{array}$ & 5.472 participantes & $\begin{array}{l}\text { - Mulheres acusadas por crimes de drogas não foram tratadas com maior } \\
\text { severidade, mas apresentaram maior probabilidade de serem presas; } \\
\text { - Mulheres de raça negra e mulheres com filhos receberam sentenças mais } \\
\text { longas; } \\
\text { - Mulheres de raça negra não foram punidas com maior severidade que } \\
\text { mulheres de raça caucasiana. }\end{array}$ \\
\hline $\begin{array}{l}\text { Spohn e Stacey } \\
\text { (2006) }\end{array}$ & E.U.A. & $\begin{array}{l}\text { Investigar o efeito das } \\
\text { variáveis sexo, estado civil e } \\
\text { ter ou não dependentes, nas } \\
\text { sentenças. }\end{array}$ & $\begin{array}{l}1.850 \text { casos, sendo } \\
1.543 \text { de sexo } \\
\text { feminino e } 307 \text { de } \\
\text { sexo masculino }\end{array}$ & $\begin{array}{l}\text { - Não se registaram diferenças na duração da pena em mulheres com } \\
\text { dependentes e mulheres sem dependentes. }\end{array}$ \\
\hline $\begin{array}{l}\text { Demuth } \\
\text { Steffensmeir } \\
(2006)\end{array}$ & e E.U.A. & $\begin{array}{l}\text { Examinar de que forma a } \\
\text { raça/etnia e o sexo influenciam } \\
\text { na atribuição de sentenças. }\end{array}$ & $\begin{array}{l}24.254 \text { participantes, } \\
\text { sendo que } 3.729 \text { eram } \\
\text { de sexo feminino e } \\
20.525 \text { de sexo } \\
\text { masculino }\end{array}$ & $\begin{array}{l}\text { - As mulheres de raça caucasiana e raça negra apresentaram percentagens } \\
\text { semelhantes de encarceramento (54\% e } 53 \% \text { respetivamente); } \\
\text { - Mulheres hispânicas apresentaram maior probabilidade de serem presas do } \\
\text { que as restantes }(67 \%) \text {. }\end{array}$ \\
\hline
\end{tabular}

- Mulheres de raça negra receberam um período maior de pena de prisão (54 meses) ao contrário de mulheres de raça caucasiana e hispânica que receberam sentenças similares e mais reduzidas ( 44 e 40 meses, respetivamente).

Mulheres com filhos tinham menor probabilidade de receber pena de prisão

- Mulheres enquadradas nos papéis de gênero tracionais tinham maior propensão a receber sentenças menos severas e a serem sancionadas com

receber medidas comunitárias ao contrário de mulheres de raça caucasiana.

ongas;

severidade que 


\begin{tabular}{lll}
\hline Brennan (2006) & E.U.A. & Averiguar de que forma a 998 indivíduos \\
& raça/etnia, empregabilidade, sexo feminino \\
& nível de escolaridade e \\
& condenações anteriores \\
& poderiam estar relacionadas \\
& com a severidade na aplicação \\
& da sentença.
\end{tabular}

de - Mulheres com filhos apresentaram 13\% mais probabilidade de serem presas;

- Mulheres casadas apresentaram 16\% menos probabilidades de serem presas;

- Mulheres com empregos apresentaram menor probabilidade de serem presas;

- Quanto maior o nível de escolaridade de uma mulher, menor a severidade da sentença aplicada;

- Mulheres com condenações anteriores apresentaram 17\% mais probabilidades de serem condenadas;

- Mulheres libertadas antes do julgamento apresentavam $19 \%$ menos de probabilidades de serem condenadas a pena de prisão, ao contrário das que foram detidas.

\begin{tabular}{|c|c|c|c|c|}
\hline $\begin{array}{l}\text { Curry, Lee } \\
\text { Rodriguez } \\
(2006)\end{array}$ & E.U.A. & $\begin{array}{l}\text { Perceber a influência do sexo } \\
\text { na produção das sentenças. }\end{array}$ & $\begin{array}{l}908 \text { participantes de } \\
\text { sexo feminino e } 5.222 \\
\text { de sexo masculino }\end{array}$ & $\begin{array}{l}\text { - As mulheres foram sobretudo beneficiadas em crimes contra a propriedade } \\
\text { e crimes relacionados com drogas; o mesmo não se verificou nos crimes } \\
\text { violentos. }\end{array}$ \\
\hline $\begin{array}{l}\text { Kruttschnitt } \\
\text { Savolainen } \\
(2009)\end{array}$ & Finlândia & $\begin{array}{l}\text { Perceber a relação entre o sexo } \\
\text { e as sentenças aplicadas. }\end{array}$ & $\begin{array}{l}1.606 \text { participantes, } \\
\text { dos quais } 1.546 \\
\text { homens e } 60 \text { mulheres }\end{array}$ & $\begin{array}{l}\text { - Nas mulheres, a situação familiar e o emprego não apresentaram um efeito } \\
\text { significativo na decisão de pena de prisão. }\end{array}$ \\
\hline $\begin{array}{l}\text { Freiburger } \\
(2010)\end{array}$ & E.U.A. & $\begin{array}{l}\text { Verificar os efeitos dos papéis } \\
\text { familiares, do sexo e da raça } \\
\text { dos juízes nas decisões } \\
\text { judiciais. }\end{array}$ & $\begin{array}{l}184 \text { juízes, dos quais } \\
37 \text { eram de sexo } \\
\text { feminino e } 147 \text { de } \\
\text { sexo masculino }\end{array}$ & $\begin{array}{l}\text { - Mulheres que cometeram crimes relacionados com drogas apresentaram } \\
\text { maior probabilidade de receber pena de prisão; } \\
\text { - Mulheres apresentaram menor probabilidade de serem presas quando o juiz } \\
\text { é de raça negra do que de raça caucasiana; } \\
\text { - Fornecer suporte financeiro e emocional foi a única variável familiar que se } \\
\text { mostrou estar relacionada com a baixa probabilidade de encarceramento em } \\
\text { mulheres de ambas as raças; } \\
\text { - Verificou-se que os antecedentes criminais eram mais importantes em } \\
\text { mulheres de raça caucasiana do que raça negra. }\end{array}$ \\
\hline $\begin{array}{l}\text { Freiburger } \\
\text { Hilinski (2010) }\end{array}$ & E.U.A. & $\begin{array}{l}\text { Compreender o efeito do sexo, } \\
\text { raça e idade nas decisões de } \\
\text { pré-julgamento. }\end{array}$ & $\begin{array}{l}2.635 \text { casos, dos quais } \\
2.187 \text { de sexo } \\
\text { masculino e } 448 \text { de } \\
\text { sexo feminino }\end{array}$ & $\begin{array}{l}\text { - Mulheres de raça negra apresentaram menor probabilidade de ser detidas ao } \\
\text { contrário de mulheres de raça caucasiana; } \\
\text { - Na maioria das vezes as mulheres eram condenadas por crimes contra a } \\
\text { propriedade; } \\
\text { - Mulheres de raça negra com } 30-39 \text { anos apresentaram menor probabilidade } \\
\text { de ser detidas do que mulheres de raça negra com mais de } 40 \text { anos, e do que } \\
\text { mulheres de raça negra de } 15-29 \text { anos. }\end{array}$ \\
\hline
\end{tabular}




\begin{tabular}{|c|c|c|c|c|}
\hline $\begin{array}{l}\text { Viglione, } \\
\text { Hannon } \\
\text { DeFina (2010) }\end{array}$ & E.U.A. & $\begin{array}{l}\text { Perceber a relação entre as } \\
\text { diferentes tonalidades de pele } \\
\text { negra e o tempo de prisão a } \\
\text { servir. }\end{array}$ & $\begin{array}{l}12.158 \text { mulheres de } \\
\text { raça negra }\end{array}$ & $\begin{array}{l}\text { - Mulheres de raça negra de pele mais clara receberam menos penas de prisão; } \\
\text { - Mulheres de pele mais clara recebem menos } 12 \% \text { de tempo em prisão, ao } \\
\text { contrário de mulheres de pele mais escura. }\end{array}$ \\
\hline $\begin{array}{l}\text { Demuth e } \\
\text { Doerner (2010) }\end{array}$ & E.U.A. & $\begin{array}{l}\text { Perceber de que forma a } \\
\text { raça/etnia, sexo e idade têm } \\
\text { influência nas sentenças } \\
\text { aplicadas. }\end{array}$ & $\begin{array}{l}33.505 \text { participantes, } \\
\text { sendo que } 27.550 \\
\text { eram de } \quad \text { sexo } \\
\text { masculino e } 5.955 \text { de } \\
\text { sexo feminino }\end{array}$ & $\begin{array}{l}\text { - Mulheres de raça hispânica, ao contrário das de raça negra e caucasiana, } \\
\text { apresentaram maior probabilidade de receber pena de prisão; } \\
\text { - Mulheres de raça caucasiana e hispânica receberam sentenças de } 4-5 \text { meses } \\
\text { mais curtas do que mulheres de raça negra; } \\
\text { - Mulheres de raça hispânica receberam sentenças } 5 \% \text { mais longas do que } \\
\text { mulheres de raça caucasiana. }\end{array}$ \\
\hline $\begin{array}{l}\text { Freiburger } \\
(2011)\end{array}$ & E.U.A. & $\begin{array}{lll}\text { Perceber a influência } & \text { dos } \\
\text { papéis } & \text { familiares } & \text { nas } \\
\text { sentenças. } & & \end{array}$ & $\begin{array}{l}426 \text { casos, sendo que } \\
121 \text { eram mulheres e } \\
305 \text { eram homens }\end{array}$ & $\begin{array}{l}\text { - Mulheres que vivem com filhos apresentaram } 81 \% \text { de probabilidades de não } \\
\text { ser presas, ao contrário das que não tem filhos; } \\
\text { - Mulheres empregadas apresentaram maior probabilidade de serem presas; } \\
\text { - Mulheres que prestam suporte financeiro à família não receberam sentenças } \\
\text { menos severas em relação a mulheres sem filhos; } \\
\text { - Um maior grau de educação no indivíduo de sexo feminino mostrou estar } \\
\text { relacionado com uma maior probabilidade de encarceramento. }\end{array}$ \\
\hline $\begin{array}{ll}\text { Freiburger } & \text { e } \\
\text { Pierce (2011) }\end{array}$ & E.U.A. & $\begin{array}{l}\text { Compreender de que forma ter } \\
\text { filhos pode influenciar na } \\
\text { sentença de } r \text { indivíduos } \\
\text { acusados de negligência } \\
\text { infantil. }\end{array}$ & $\begin{array}{l}434 \text { participantes, dos } \\
\text { quais } 271 \text { eram de } \\
\text { sexo feminino e } 163 \\
\text { de sexo masculino }\end{array}$ & $\begin{array}{l}\text { - Mulheres que cometem crimes de negligência infantil são tratadas com } \\
\text { maior severidade, ao contrário de mulheres que cometem outros tipos de } \\
\text { crimes. }\end{array}$ \\
\hline $\begin{array}{l}\text { Hartley et al. } \\
\text { (2011) }\end{array}$ & $\begin{array}{l}\text { Coreia do } \\
\text { Sul }\end{array}$ & $\begin{array}{l}\text { Examinar a disparidade nas } \\
\text { sentenças em termos de sexo }\end{array}$ & $\begin{array}{l}2.479 \text { casos, dos quais } \\
2.041 \text { eram de sexo } \\
\text { masculino e } 438 \text { de } \\
\text { sexo feminino }\end{array}$ & $\begin{array}{l}\text { - Mulheres com emprego recebem punições mais severas que mulheres } \\
\text { desempregadas; } \\
\text { - Mulheres com antecedentes criminais relacionados com drogas receberam } \\
\text { punições mais severas que mulheres sem antecedentes; } \\
\text { - Mulheres que enveredam em atividades criminais tipicamente "masculinas" } \\
\text { recebem punições mais severas. }\end{array}$ \\
\hline $\begin{array}{l}\text { Freiburger e } \\
\text { Hilinski (2013) }\end{array}$ & E.U.A. & $\begin{array}{l}\text { Compreender de que forma a } \\
\text { raça, o sexo e a idade têm } \\
\text { influência na aplicação das } \\
\text { sentenças. }\end{array}$ & $\begin{array}{l}2.011 \text { casos dos quais } \\
780 \text { de sexo feminino } \\
\text { e } 1.231 \text { de sexo } \\
\text { masculino }\end{array}$ & $\begin{array}{l}\text { - Mulheres de raça caucasiana ( } 40 \text { anos ou mais) apresentaram menor } \\
\text { probabilidade de serem sentenciadas com liberdade condicional ao contrário } \\
\text { de mulheres mais jovens de raça caucasiana ( } 17 \text { a } 29 \text { anos); } \\
\text { - Mulheres de raça caucasiana ( } 40 \text { ou mais) e mulheres de raça negra ( } 30 \text { a } 39 \\
\text { anos) tinham menor probabilidade de serem condenadas a pena de prisão ao } \\
\text { contrário de mulheres de raça caucasiana ( } 17 \text { a } 29 \text { anos). }\end{array}$ \\
\hline
\end{tabular}




\begin{tabular}{|c|c|c|c|c|}
\hline $\begin{array}{l}\text { Demuth e } \\
\text { Doerner (2014) }\end{array}$ & E.U.A. & $\begin{array}{l}\text { Examinar de que maneira o } \\
\text { sexo tem influência nas } \\
\text { decisões judiciais. }\end{array}$ & $\begin{array}{l}\text { 109.181 participantes, } \\
\text { dos quais } 90.297 \text { eram } \\
\text { de sexo masculino e } \\
18.884 \text { de sexo } \\
\text { feminino }\end{array}$ & $\begin{array}{l}\text { - Mulheres de raça negra receberam sentenças } 4 \% \text { menos severas que } \\
\text { mulheres de raça caucasiana; } \\
\text { - Ter antecedentes criminais estava relacionado com sentenças longas; } \\
\text { - Ter o secundário ou um maior grau de educação mostrou ter influência na } \\
\text { aplicação de sentenças em mulheres, ou seja, receberam sentenças menos } \\
\text { longas. }\end{array}$ \\
\hline Doerner (2015) & E.U.A. & $\begin{array}{l}\text { Examinar a relação das } \\
\text { variáveis sexo e raça/etnia na } \\
\text { aplicação das sentenças. }\end{array}$ & 111.123 casos & $\begin{array}{l}\text { - Mulheres hispânicas e mulheres de raça negra apresentaram menor } \\
\text { probabilidade de receberem pena de prisão, ao contrário de mulheres de raça } \\
\text { caucasiana; } \\
\text { - Ter antecedentes criminais e ter sido detida antes da sentença resulta numa } \\
\text { pena maior; } \\
\text { - Mulheres que completaram o ensino secundário apresentaram maior } \\
\text { probabilidade de receber sentenças mais curtas, ao contrário das que não o } \\
\text { completaram. }\end{array}$ \\
\hline $\begin{array}{lll}\text { Frank } & \text { et } & \text { al. } \\
(2015) & & \end{array}$ & E.U.A. & $\begin{array}{l}\text { Analisar as disparidades tendo } \\
\text { em conta a variável sexo na } \\
\text { aplicação de sentenças. }\end{array}$ & 3.593 participantes & $\begin{array}{l}\text { - Mulheres de raça negra apresentaram maior probabilidade de serem } \\
\text { sentenciadas a pena de prisão, ao contrário de mulheres de raça caucasiana; } \\
\text { - Mulheres de raça negra e caucasiana, quando sentenciadas com pena de } \\
\text { prisão receberam aproximadamente o mesmo tempo de pena. }\end{array}$ \\
\hline $\begin{array}{l}\text { Freiburger e } \\
\text { Sheeran (2017) }\end{array}$ & E.U.A. & $\begin{array}{l}\text { Examinar de que forma as } \\
\text { variáveis raça, etnia, sexo e } \\
\text { idade têm influência nas } \\
\text { decisões judiciais. }\end{array}$ & $\begin{array}{l}5.907 \text { casos, sendo } \\
\text { que } 751 \text { eram de sexo } \\
\text { feminino e } 5.156 \text { de } \\
\text { sexo masculino }\end{array}$ & $\begin{array}{l}\text { - Mulheres de raça negra apresentaram maior probabilidade de receber } \\
\text { liberdade condicional em vez de pena de prisão; } \\
\text { - Mulheres de raça caucasiana mais novas (17-29 anos) e de raça negra mais } \\
\text { novas (17-29 anos), apresentaram maior probabilidade de receber liberdade } \\
\text { condicional do que pena de prisão. }\end{array}$ \\
\hline
\end{tabular}




\section{Resultados descritivos dos 30 estudos}

Ano de publicação, localização geográfica, caracterização da amostra

Os anos de publicação dos 30 estudos selecionados variaram entre 1980/81 (Kruttschnitt, 1980-1981) e 2017 (Freiburger e Sheeran, 2017), sendo que mais de dois terços dos estudos foram publicados a partir de 2000.

Analisando os referidos artigos, foi possível verificar-se que a maioria dos estudos foram realizados nos E.U.A. (n=28: $\quad$ Kruttschnitt, $\quad$ 1980-1981; Kruttschnitt, 1982; Gruhl, Spohn e Welch, 1985; Daly, 1987; Daly, 1989;

Bickle e Peterson, 1991; Spears e Spohn, 1997; Steffensmeier et al., 1998; Williams, 1999; Beichner e Spohn, 2000; Albonetti, 2002; Koon-witt, 2002; Griffin e Wooldredge, 2006; Spohn e Stacey, 2006; Demuth e Steffensmeier, 2006; Brennan, 2006; Curry, Lee e Rodriguez, 2006; Freiburger, 2010; Freiburger e Hilinski, 2010; Viglione, Hannon e DeFina, 2010; Demuth e Doerner, 2010; Freiburger, 2011; Freiburger e Pierce, 2011; Freiburger e Hilinski, 2013; Demuth e Doerner, 2014; Doerner, 2015; Frank et al., 2015;
Freiburger e Sheeran, 2017), tendo sido também encontrados estudos na Finlândia $\quad(n=1 ; \quad$ Kruttschnitt $\quad \mathrm{e}$ Savolainen, 2009) e na Coreia do Sul ( $n=1$; Hartley et al., 2011).

Relativamente à caracterização da amostra, e analisando a tabela 1, constatou-se que pese embora a maioria dos estudos desenvolvidos na área da disparidade de sentenças tivesse contemplado nas suas amostras participantes de sexo feminino e masculino, verificou-se a existência de diversos tipos de amostra: estudos que incluíram indivíduos de ambos os sexos (n=22: Gruhl, Spohn e Welch, 1985; Daly, 1987; Daly, 1989, Bickle \& Peterson, 1991; Spears \& Spohn, 1997; Williams, 1999; Beichner e Spohn, 2000; Albonetti, 20002; Koons-witt, 2002; Spohn e Stacey, 2006; Demuth e Steffensmeier, 2006; Curry, Lee e Rodriguez, 2006; Kruttschnitt e Savolainen, 2009; Freiburger, 2010; Freiburger e Hilinski, 2010; Demuth e Doerner, 2010; Freiburger, 2011; Freiburger e Pierce, 2011; Hartley et al., 2011; Freiburger e Hilinski, 2013; Demuth e Doerner, 2014; Freiburger e Sheeran, 2017), estudos que envolveram apenas mulheres $(n=4$ : Kruttschnitt, 
1980-1981; Kruttschnitt, 1982; Brennan, 2006; Viglione, Hannon e DeFina, 2010) e outros estudos onde não foi discriminada a constituição da amostra no que ao sexo diz respeito $(n=4$ : Steffensmeier et al., 1998; Griffin e Wooldredge, 2006; Doerner, 2015; Frank et al., 2015), embora nas conclusões fizessem menção às mulheres. Relativamente ao tamanho da amostra, a mesma variou entre 3 participantes (Daly, 1989) e 18.884 (Demuth e Doerner, 2014), sendo de referir que estes dois estudos apenas contemplaram mulheres.

No que diz respeito à caracterização etária da amostra, importa referir que em todos os estudos analisados se encontraram apenas indivíduos maiores de idade, dado que este constituía um critério de inclusão na presente revisão. Finalmente, no que diz respeito à etnia/raça dos/as participantes foi possível verificar que das amostras utilizadas, apenas foram consideradas relevantes para o estudo da disparidade das sentenças, indivíduos de raça negra, caucasiana e hispânica.

\section{Fatores promotores de disparidades ao nível das sentenças}

Através da análise dos 30 estudos considerados na presente revisão, foi possível constatar-se a existência de múltiplos fatores que tendem a promover disparidades ao nível das sentenças judiciais, e que a seguir se descrevem (e.g., a idade, a existência de filhos/dependentes, a raça/etnia, o tipo de crime praticado, a escolaridade, a existência de antecedentes criminais).

No que diz respeito à faixa etária dos participantes que integraram as amostras dos diferentes estudos, foi possível verificar num estudo (Beichner e Spohn, 2000) que as mulheres inseridas em faixas etárias mais altas (mais de 30 anos) apresentavam maior probabilidade de lhes ser aplicada uma pena de prisão. Outros dois estudos (Freiburger e Hilinski, 2013; Freiburger e Sheeran, 2017) verificaram que mulheres de faixas etárias mais baixas (17-29 anos) apresentavam maior probabilidade de receber liberdade condicional ao invés de pena de prisão. Contrariamente, verificou-se no mesmo estudo (Freiburger e Hilinski, 2013) que mulheres de faixas etárias mais altas apresentaram menor probabilidade de receber pena de prisão quando comparadas com mulheres de faixas etárias mais novas. 
Relativamente à existência de filhos/dependentes foi possível apurar resultados divergentes entre os diversos estudos analisados. Assim em dois estudos (Brennan, 2006; Griffin e Wooldredge, 2006) verificou-se que mulheres com filhos/dependentes apresentaram maior probabilidade de lhes ser deduzida pena de prisão ao contrário de mulheres sem filhos/dependentes (Brennan, 2006), bem como receberem penas mais longas (Griffin e Wooldredge, 2006). Por sua vez, outros estudos comprovaram que mulheres com filhos/dependentes exibiam menor probabilidade de serem condenadas a pena de prisão (Beichner e Spohn, 2000; Freiburger, 2011; Koonswitt, 2002), assim como a receberem penas menos severas (Daly, 1987). Além destes resultados, dois outros estudos (Beichner e Spohn, 2000; Daly, 1989) comprovaram que o tratamento preferencial dos juízes se encontrava positivamente relacionado com o facto de as mulheres terem filhos.

Também em relação à detenção se encontraram resultados mistos: comparando mulheres de raça negra com as caucasianas, as mulheres de raça negra tinham menor probabilidades de serem detidas ao invés das mulheres de raça caucasiana (Freiburger e Hilinski, 2010), assim como de receberem penas menos severas que as mesmas (Demuth e Doerner, 2014); por sua vez, outros estudos (Albonetti, 2002; Demuth e Doerner, 2010) mostraram que mulheres de raça negra foram alvo de um período maior de pena de prisão ao contrário de mulheres de raça caucasiana e hispânica, bem como apresentaram maior probabilidade de serem sentenciadas com pena de prisão ao contrário das mulheres de raça caucasiana (Beichner e Spohn, 2000; Frank et al., 2015); dois estudos (Demuth e Steffensmeier, 2006; Spears e Spohn, 1997) demonstraram existir a mesma probabilidade de pena de prisão em mulheres de raça caucasiana e raça negra, assim como quando sentenciadas com pena de prisão receberem aproximadamente o mesmo tempo de pena (Frank et al., 2015); no que diz respeito às mulheres hispânicas, os estudos que consideraram este grupo (Demuth e Steffensmeier, 2006; Demuth e Doerner, 2010), apontaram para a sua maior probabilidade de serem condenadas a pena de prisão ao contrário das mulheres de outras raças. Já no que toca à severidade das penas, um estudo (Steffensmeier et al., 1998) concluiu que as mulheres de raça negra foram 
condenadas com maior severidade ao contrário de mulheres de raça caucasiana, sendo que outro estudo (Griffin e Wooldredge, 2006) concluiu exatamente o contrário.

Tomando em consideração o crime praticado, foi possível verificar que as mulheres são penalizadas ou beneficiadas também em função do tipo de crimes por si praticados como vamos enunciar de seguida. Quanto aos crimes relacionados com drogas, alguns estudos (e.g. Griffin e Wooldredge, 2006; Freiburger, 2010; Curry, Lee e Rodriguez, 2006) revelaram que as mulheres não eram condenadas com maior severidade, no entanto apresentavam maior probabilidade de receber pena de prisão (Griffin e Wooldredge, 2006, Freiburger, 2010). Contrariamente, um outro estudo (Curry, Lee e Rodriguez, 2006) mostrou que as mulheres eram beneficiadas quando cometiam crimes contra a propriedade, crimes relacionados com drogas e eram mais punidas em crimes violentos.

Por fim e no que respeita à relação entre os papéis de gênero que são atribuídos pela sociedade às mulheres e o tipo de crime cometido por estas, verificou-se que as mulheres que se envolviam em crimes (e.g., maus tratos a
84

menores, negligência infantil, infanticídio, abuso sexual de menores, entre outros) que transgridem os papéis de gênero apresentavam maior probabilidade de sofrerem punições mais severas. Mais concretamente e no que se refere à negligência infantil, um estudo (Freiburger \& Pierce, 2011) demonstrou que as mulheres que cometeram este tipo de crimes foram tratadas com maior severidade do que as que cometeram outros tipos de crimes. Assim, foi possível verificar que mulheres que assumiram algum tipo de identificação com os papéis de gênero tradicionais apresentaram maior probabilidade de receberem penas menos severas (Koonswitt, 2002). No entanto, quando as mesmas enveredavam por atividades tipicamente "masculinas", tendiam a receber punições mais severas (Hartley et al., 2011).

Relativamente à escolaridade verificou-se num estudo (Freiburger, 2011) que um maior grau de educação nas mulheres se encontrava associado a uma maior probabilidade de receber pena de prisão. Contrariamente, outros estudos (e.g., Demuth e Doerner, 2014; Doerner, 2015) revelaram que ter um maior grau de educação estava relacionado com a atribuição de penas 
mais curtas e uma menor severidade nas mesmas (Brennan, 2006). O mesmo se verificou em relação à empregabilidade, e em que as mulheres ativas do ponto de vista profissional apresentavam maior probabilidade de serem presas (Freiburger, 2011), assim como se verificou que as mesmas receberam penas mais severas (Hartley et al., 2011). Contrariamente, outros estudos (Brennan, 2006) apuraram que mulheres inseridas profissionalmente apresentavam menor probabilidade em serem presas assim como maior probabilidade em receberem sentenças menos severas (Kruttschnitt, 19801981). Apenas um estudo (Bickle e Peterson, 1991) concluiu não existir quaisquer implicações entre inserção profissional e a tomada de decisão judicial.

Em termos de história criminal, as mulheres com antecedentes criminais apresentaram maior probabilidade de serem condenadas (Brennan, 2006), constituindo este um fator importante na tomada de decisão e na severidade das sentenças a aplicar em indivíduos de sexo feminino (Kruttschnitt, 1982). Neste sentido, a presença de história criminal surgiu associada a penas mais longas (Demuth e Doerner, 2014;
Doerner, 2015) e à severidade da mesma (Kruttschnitt, 1980-1981). Relativamente à raça/etnia, os antecedentes criminais mostraram ser mais importantes para mulheres de raça caucasiana do que para mulheres de raça negra (Freiburger, 2010).

Para além destes fatores enunciados acima, identificaram-se outros (e.g., situação económica, problemas psiquiátricos e estado civil) que não obtiveram o mesmo desenvolvimento nos diferentes estudos, mas que ainda assim nos parece importante apresentar. Assim, foi possível verificar que a probabilidade de uma mulher receber uma sentença severa aumentava se a mesma fosse economicamente desfavorecida (Kruttschnitt, 1980-1981); por sua vez, fornecer suporte financeiro e emocional foi a única variável familiar que se mostrou estar relacionada com a baixa probabilidade de encarceramento em mulheres de ambas as raças (Freiburger, 2010). Relativamente ao estado civil, apenas um estudo (Brennan, 2006) revelou que mulheres casadas apresentavam menor probabilidade de serem condenadas a pena de prisão. Por fim, também um único estudo (Kruttschnitt, 1982) revelou que 
mulheres com história de problemas psiquiátricos tendiam a receber sentenças mais severas.

\section{Discussão e conclusões}

Através desta revisão estruturada da literatura foi possível perceber e documentar um aumento progressivo da investigação em matéria de criminalidade feminina e mais concretamente, ao nível da análise da relação da mulher criminal com o sistema de justiça. Contudo, a grande maioria dos estudos desenvolvidos neste âmbito situam-se nos E.U.A., sobretudo a partir dos anos 2000, carecendo-se ao nível nacional e europeu de estudos neste sentido que procurem, em concreto, analisar as disparidades ao nível das sentenças atribuídas exclusivamente a indivíduos de sexo feminino. De notar que a grande maioria dos estudos contemplou amostras mistas em termos de sexo. Da análise dos estudos, com enfoque na forma como a mulher criminal é percecionada e julgada pelo sistema de justiça, foi possível identificar uma ampla variedade de fatores que poderão contribuir para atenuar ou agravar as penas atribuídas, nomeadamente: a idade, a existência de filhos/dependentes, a raça/etnia, o tipo de crime praticado, a escolaridade, os antecedentes criminais e outros fatores, como mencionado anteriormente. Contudo, nem todos os fatores possuem igual peso na tomada de decisão judicial.

Nos estudos apresentados emergiram duas ideias distintas quanto ao fator existência de filhos: alguns estudos (Brennan, 2006; Griffin e Wooldredge, 2006) apontaram que mulheres com filhos/dependentes apresentavam maior probabilidade de receberem pena de prisão, enquanto que outros estudos (Beichner e Spohn, 2000; Freiburger, 2011; Koons-witt, 2002) mostraram que ter filhos/dependentes se encontrava associado a uma menor probabilidade de condenação a pena de prisão. Assim em dois estudos (Daly, 1989; Freiburger, 2010) realizados com juízes de ambos os sexos, foi possível constatar que a existência de filhos/dependentes é uma variável importante na determinação da sentença (Daly, 1989), sendo que os juízes parecem tomar as suas decisões com base no tipo tradicional de parentalidade (Kaukinen, 1995). Mulheres que não providenciam suporte/cuidam dos seus filhos/dependentes tendem a ser punidas mais severamente, na medida em que são percecionadas como violadoras da 
norma social (Freiburger, 2010). Efetivamente e de acordo com Daly (1989), as decisões judiciais podem ser baseadas em função do enquadramento familiar, ou seja, arguidos/as prestadores de cuidados tendem a ser sentenciados com menor severidade, podendo isto ser melhor compreendido através dos pressupostos da teoria do paternalismo, a qual sustenta que a existência de atitudes protetores por parte dos juízes para com indivíduos que desempenham um papel nuclear no seio da família. Tem sido igualmente sustentado que, para os juízes, as maiores dificuldades em condenar homens/mulheres de família passa pela punição de inocentes (nestes casos os filhos/dependentes), a separação das famílias, a remoção de suporte financeiro e cuidados, bem como a existência de elevados custos monetários para o estado em manter as mulheres presas e colocar crianças em instituições (Daly, 1989). Em concordância Koons-witt (2002) refere que, neste tipo de casos, as mulheres tendem a ser julgadas com menor severidade, de forma a preservar a integridade das famílias e evitar possíveis ruturas. Além disso, Freiburger (2010) acrescenta que indivíduos com famílias apresentam mais responsabilidades (cuidar de crianças, ter emprego, etc) e por esse motivo são menos propensos a reincidir. Assim, como referido anteriormente, a aplicação de penas menos severas a mulheres que possuem a seu cargo filhos/dependentes tem sido atribuída ao facto de o sistema atender não só aos custos sociais que as suas punições apresentam para a sociedade bem como o "sofrimento" que as medidas judiciais poderão acarretar no bem-estar e manutenção da família (Daly, 1987; Freiburger, 2010). Em contrapartida, outros estudos (Brennan, 2006; Griffin e Wooldredge, 2006; Koons-witt, 2002) encontraram uma maior probabilidade destas mulheres receberem pena de prisão, ao contrário do que seria espectável. Tem sido sustentado que o encarceramento da mãe, por oposição à atribuição de penas mais brandas, poderá constituir uma forma de o poder judicial melhor proteger a criança (Koons-witt, 2002), na medida em que estas mães tendem a ser percecionadas como possuindo um estilo de vida irresponsável, suscetível de por em causa o desenvolvimento da criança (Spohn, 1999). A atribuição de penas mais severas a mulheres com filhos parece também estar relacionada com o tipo de crime por si praticado sobretudo 
se este atentar as prescrições socialmente estabelecidas. A este propósito, Hagan e Nagel (1983), sustentam que as mulheres tendem a receber penas mais longas quando a sua conduta criminal contraria os estereótipos de gênero estabelecidos ou praticam crimes tipicamente masculinos. Estas mulheres que adotam este tipo de conduta criminal tendem a ser percebidas pelos juízes como sendo perigosas para os seus filhos/dependentes (Griffin e Wooldredge, 2006).

Por sua vez, indivíduos com determinadas características (raça negra e hispânica) tendem a ser mais facilmente considerados culpados e com maior predisposição para a prática de atividades criminosas. Efetivamente, na presente revisão, alguns estudos (Albonetti, 2002; Demuth e Doerner, 2010) verificaram que indivíduos de sexo feminino de raça negra receberam um período maior de pena de prisão, existindo igualmente uma maior probabilidade de serem sentenciadas com pena de prisão ao contrário do que sucede com mulheres de raça caucasiana (Beichner e Spohn, 2000; Frank et al., 2015). Não obstante, outros estudos (Freiburger e Hilinski, 2010; Demuth e Doerner, 2014) apontaram no sentido contrário. Esta atribuição de penas mais severas, com base na etnia e na raça dos ofensores, tem sido atribuída à existência de estereótipos sociais em torno de determinadas características (raça/etnia) que mais facilmente tendem a surgir acopladas a perceções de culpabilidade, perigosidade e maior risco de reincidência (Albonetti, 1997; Steffensmeier et al., 1998).

No que respeita às características do crime praticado, estas parecem desempenhar um papel determinante na atribuição de sentenças a mulheres, sobretudo quando colidem com os papéis de gênero (Smart, 1976 citado por Silva, 2013). Neste sentido, mulheres que pratiquem crimes considerados "masculinos" são punidas com maior severidade uma vez que violam os estereótipos de gênero (Hagan e Nagel, 1983). Tal parece verificar-se, por exemplo, nas situações em que as mulheres praticam crimes violentos, o mesmo não se sucedendo quando estão em causa crimes de outra natureza (e.g., crimes contra a propriedade). O gênero surge, deste modo, como um fator promotor de disparidades ao nível das sentenças judiciais, sobretudo quando a conduta criminal feminina não está em conformidade com os estereótipos de 
gênero (Curry, Lee e Rodriguez, 2006). Note-se que o gênero continua a desempenhar um papel fundamental no processo de socialização dos indivíduos, ditando expectativas diferenciadas acerca do que deverá ser a conduta, feminina e masculina, aceitável. Resulta, deste modo, que homens e mulheres são, em regra, socializados para desempenhar papéis de gênero específicos e distintos (e.g., os homens são incentivados a apresentar um comportamento mais agressivo, dominador e as mulheres são desafiadas para adoção de um comportamento mais passivo, de submissão face ao outro) sendo que tal irá influenciar inequivocamente as atitudes face ao crime (Page, 2008).

Relativamente aos antecedentes criminais este constitui igualmente um fator determinante ao nível da tomada de decisão judicial (atribuição de uma maior severidade da pena) dado que nestas circunstâncias é conhecida a maior probabilidade de reincidência e de adoção de comportamentos criminosos futuros (Steffensmeier et al., 1998).

Em conclusão, verificámos através da análise destes 30 estudos que existem fatores que desempenham um papel determinante na tomada de decisão judicial, contudo o peso destes fatores parece oscilar, sendo que aqueles que estão mais associados aos papéis de gênero parecem impactar de forma mais significativa na atribuição de sentenças mais severas (e.g., existência de filhos/dependentes, o tipo de crime praticado e os antecedentes criminais), havendo outros que contribuem fundamentalmente para atenuar a sanção atribuída à mulher (e.g., existência de filhos/dependentes, idade, raça/etnia) e outros ainda que parecem influenciar, de forma independente das questões de gênero (e.g., escolaridade, empregabilidade). De igual modo, foram detetadas algumas divergências no que respeita à influência que muitos destes fatores poderão ter na tomada de decisão judicial e as quais poderão, em parte, ser explicadas não só pelas especificidades metodológicas dos diferentes estudos, mas também pelas questões culturais e enquadramento legal onde os aludidos estudos foram conduzidos.

Pese embora a existência de resultados mistos em muitos dos fatores analisados, no geral percebe-se que a forma como o sistema de justiça atua em casos que envolvem a mulher enquanto agente criminal está ainda muito ligado a expectativas e normativas genderizadas tal como demonstrado em outros 
trabalhos (cf. Caridade e Nunes, 2017). Mais concretamente, homens e mulheres com similares ofensas tendem a receber um tratamento judicial distinto e em que: i) o sistema de justiça tende a exibir uma certa benevolência na atribuição de penas a certas condutas criminais femininas (o caso das ofensas sexuais); ii) as mulheres apresentam duas vezes mais de probabilidades de receberem tratamento psiquiátrico pelo sistema judicial (medicação ou internamento psiquiátrico); iii) subsistem argumentos que contestam a agência criminal feminina; e, por fim, iii) a adoção de posicionamentos que pendem para uma dupla transgressão feminina, sempre que se verifica uma relação de proximidade entre a mulher ofensora e a vítima e quando esta relação tem ligação com os papéis de gênero (sobretudo no caso da maternidade e conjugalidade), resultando, neste caso, em medidas mais severas para com a mulher (Caridade e Nunes, 2017).

Fica, pois, claro que as reações sociais e formais ao comportamento feminino (normativo ou criminal) estão, ainda, muito imbuídas de prescrições sociais e culturais rígidas e polarizadas. Neste sentido, a forma como as mulheres são percecionadas pela sociedade e pelo sistema judicial em particular (cuidadoras, dependentes e vítimas das circunstâncias), escamoteia a sua eventual perigosidade, culpa e responsabilidade por certas infrações criminais, conduzindo, por conseguinte, a sanções punitivas mais brandas (Jeffries, 2002).

\section{Referências dos estudos considerados na revisão estruturada}

Albonetti, Celesta (1997), "Sentencing under the federal sentencing guidelines: Effects of defendant characteristics, guilty pleas, and departures on sentence outcomes for drug offenses", Law \& Society Review, 31(4), 789-822.

Albonetti, Celesta (2002), "Gender and ethnicity on length of imprisonment under the federal sentencing guidelines for drug trafficking/ manufacturing offenders", The Journal of Gender, Race \& Justice, 6, 39-60.

Amâncio, Lígia (1994), Masculino e feminino. A construção social $d a$ diferença. Porto: Afrontamento. 
Beichner, Dawn; Spohn, Cassia (2000), "Is preferential treatment of female offenders a thing of the past? A multisite study of gender, race, and imprisonment", Criminal Justice Policy Review, 11(2), 149-184.

Bickle, Gayle; Peterson, Ruth (1991), "The impact of gender-based family roles on criminal sentencing", Problems, 38(3), 372-394.

Brennan, Pauline (2006), "Sentencing female misdemeanants: An examination of the direct and indirect effects of race/ethnicity, Justice Quarterly, 23(1), 60-95.

Caridade, Sónia; Nunes, Laura (2017), "Gênero, sistema de justiça criminal e controlo social: uma análise sobre o crime feminino", in Jorge Trindade e Fernanda Molinari (orgs.), Portugal. Psicologia Forense: Novos Caminhos. Porto Alegre: Imprensa Livre, 305-322.

Cauffman, Elizabeth (2008), "Understanding female offender", The Future of Children, 18(2), 119-142.

Curry, Theodore; Lee, Gang; Rodriguez, Fernando (2006), “Gender differences in criminal sentencing: Do effects vary across violent, property, and drug offenses?", Social Science Quarterly, 87(2), 318-339.

Daly, Kathleen (1987), "Discrimination in the criminal courts: Family, gender, and the problem of equal treatment", Social Forces, 66(1), 152-175.

Daly, Kathleen (1989), "Rethinking judicial paternalism: gender, workfamily relations, and sentencing", Gender \& Society, 3(1), 9-39.

Demuth, Stephen; Steffensmeier, Darrell (2006), "Does gender modify the effects of race-ethnicity on criminal sanctioning? Sentences for male and female white, black, and hispanic defendants", Journal Quantitative Criminology, 22, 241-261.

Demuth, Stephen; Doerner, Jill (2010), "The independent and joint effects of race/ethnicity, Gender, and age on sentencing outcomes in U.S. federal courts", Justice Quarterly, 27(1), 1-27.

Demuth, Stephen; Doerner, Jill (2014), "Gender and sentencing in the federal courts: Are women treated more 
leniently?", Criminal Justice Policy

Review, 25(2), 242-269.

Doerner, Jill (2015), “The joint effects of gender and race/ethnicity on sentencing outcomes in federal courts", Women \& Criminal Justice, 25, 313-338.

Duarte, Vera (2012), Discursos e percursos na delinquência juvenil feminina. Lisboa: Húmus.

Frank, James et al. (2015), "From initial appearance to sentencing: Do female defendants experience disparate treatment?", Journal of Criminal Justice, 43, 406-417.

Franklin, Cortney; Fearn, Noelle (2008), "Gender, race, and formal court decision-making outcomes: Chivalry/ paternalism conflict theory or gender conflict?", Journal of Criminal Justice, 36, 279-290.

Freiburger, Tina (2010), "The effects of gender, family status, and race on sentencing decisions", Behaviour Sciences and the Law, 28, 378-395.

Freiburger, Tina (2011), "The impact of gender, offense type, and family role on the decision to incarcerate". Social Justice Research, 24, 143-167. Freiburger, Tina; Hilinski, Carly (2010), "The impact of race, gender, and age on the pretrial decision", Criminal Justice Review, 35(3), 318-334.

Freiburger, Tina; Hilinski, Carly (2013), "An examination of the interactions of race and gender on sentencing decisions using a trichotomous dependent variable", Crime \& Delinquency, 59(1), 59-86.

Freiburger, Tina; Pierce, Mari (2011), "Assessing the influence of familial paternalism on child neglect sentencing decisions", American Journal of Criminal Justice, 36, 421-433.

Freiburger, Tina; Sheeran, Alyssa (2017), "The join effects of race, ethnicity, gender, and age on the incarceration and sentence lenght decisions", Race and Justice, $\mathrm{XX}(\mathrm{X}), 1$ 20.

Griffin, Timothy; Wooldredge, John (2006), "Sex based disparities in felony dispositions before versus after sentencing reform in Ohio", Criminology, 44(4), 893-923. 
Gruhl, John; Spohn, Cassia; Welch, Susan (1985), "Women defendants in court: the interaction between sex and race in convicting and sentencing.", Social Science Quarterly, 66(1), 178185.

Hagan, John; Nagel, Ilene (1983), "Gender and crime: Offense patterns and criminal court sanctions", The University of Chicago Press Journals, 4, 91-144.

Hartley, Richard et al. (2011), "Exploring sex disparity in sentencing outcomes: A focus on narcotics offenders in South Korea”, International Journal of Offender Therapy and Comparative Criminology, 55(2), 268286.

Jeffries, Samantha (2002), "Does gender really matter? Criminal court decision making in New Zealand", New Zealand Sociology, 17(1),135-149.

Kaukinen, Catherine (1995), Women lawbreakers constructed in terms of traditional definitions of femininity: The sentencing of women in conflict with the law (Tese de mestrado não publicada).

University of Windsor.

Koons-Witt, Barbara (2002), “The effect of gender on the decision to incarcerate before and after the introduction of sentencing guidelines", Criminology, 40(2), 297-327.

Kruttschnitt, Candace (1980-1981), "Social status and sentences of female offenders", Law \& Society Review, 15(2), 247-266.

Kruttschnitt, Candace (1982), "Respectable women and law", The Sociological Quarterly, 23(2), 221-234.

Kruttschnitt, Candace; Savolainen, Jukka (2009), "Ages of chivalry, places of paternalism", European Journal of Criminology, 6(3), 225-247.

Machado, Helena (2004), "Cidadania polifónica e a (in)justiça para as mulheres", Ex-aequo: revista da Associação Portuguesa de Estudos sobre as Mulheres, 13-26.

Matos, Raquel (2008), Vidas raras de mulheres comuns. Percursos de vida, significações do crime e construção da 
identidade em jovens reclusas. Coimbra:

Almedina.

Nogueira, Conceição (2001). Um novo olhar sobre as Relações Sociais de Género. Feminismo e perspectivas críticas na Psicologia Social. Lisboa: Fundação Calouste de Gulbenkian.

Page, Amy (2008), "Judging women and defining crime: Police officers' attitudes toward women and rape", Sociological Spectrum, 28, 389-411.

Philippe, Arnaud (2017), “Gender disparities in criminal justice", Toulouse School of Economics, (17-762), 2-32.

Silva, Vera (2013), “Controlo e punição: As prisões para mulheres", Ex Aequo, (28), 59-72.

Spears, Jeffrey; Spohn, Cassia (1997), "Gender and case processing decisions", Women \& Criminal Justice, 8(3), 29-59. Spohn, Cassia (1999), “Gender and sentencing of drug offenders: Is chivalry dead?", Criminal Justice Policy Review, 9(3), 365-399.

Spohn, Cassia; Stacey, Ann (2006), "Gender and the social costs of sentencing: An analysis of sentences imposed on male and female offenders in three U.S. district courts", Berkeley Journal of Criminal Law, 11(2), 43-76. Steffensmeier, Darrell et al. (1998), "The interaction of race, gender, and age in criminal sentencing: the punishment cost of being young, black, and male", Criminology, 36(4), 763-798.

Viglione, Jill; Hannon, Lance; Defina, Robert (2011). The impact of light skin on prison time for

black female offenders. The Social Science Journal, 48, 250-258.

Williams, Marian (1999). Gender and sentencing: An analysis of indicators. CJPR, 10(4), 471-490. 